\title{
Awareness among Pharmacy Students about Generic Medicines: A Cross-Sectional Study
}

\author{
Reshal Dsouza, Ruman Abdul Khader, Sannidhi Shanker, Shaba Fathima, Bharath Raj K C*, Shreyas K, Nidhi K, Sinchana R Shetty \\ Department of Pharmacy Practice, NGSM Institute of Pharmaceutical Sciences, NITTE (Deemed to be University), Mangaluru, Karnataka, INDIA.
}

\begin{abstract}
Introduction: A generic drug is a pharmaceutical product that is commonly used in place of branded medicine. Generic medications have the same therapeutic effect as their branded counterparts. The utilisation of generic drugs is critical for lowering rising health-care costs, and pharmacy students must have a thorough understanding of generic medications. Methodology: The present study was performed to assess the awareness about generic medicines among first-year and fourth-year bachelor of pharmacy students at a college in Coastal Karnataka, India. An awareness questionnaire was prepared and validated, and distributed to the students. Simple descriptive statistics were used to produce frequencies, percentages, and proportions. Microsoft Excel was used to analyze the data. During the study, 200 students were enrolled. 10 questions were asked out of that students' answers were validated, and they showed comparatively good knowledge about generic medicines. Results: Out of 200 students, 181 students answered that Generic drugs are available in Jan-Aushadi, 183 students think that there is a price variation between generic drugs and branded drugs, 123 students approved that generic medicines are equivalent to branded drugs, 156 students have agreed that there is no difference in the effectiveness of generic drugs and branded drugs, 114 students not agreed that generic drugs have long duration of action than branded drugs, 87 students have the opinion that both branded
\end{abstract}

and generic drugs are made in same manufacturing facilities. Conclusion: The study confirmed that fourth-year students had better awareness about generic drugs compared to first-year students. There was a significant gap concerning the knowledge about generic medicines. Studies among pharmacy students in the institution are required. More work is required on how interventions for pharmacy students and the community can result in an increase in the awareness and acceptability of generic medicines. Awareness gaps about the use of generic medicines exist, and they must be corrected through suitable education. Deficiencies were noted, and we have to strengthen learning about generic medicines during the coming years.

Key words: Generic drugs, Jan-Aushadi, Branded drugs, Awareness, Effectiveness.

Correspondence

Mr. Bharath Raj K C,

Department of Pharmacy Practice, NGSM Institute of Pharmaceutical Sciences, NITTE (Deemed to be University), Mangaluru-575018, Karnataka, INDIA.

Email id: bharathraj@nitte.edu.in

DOI: 10.5530/jyp.2022.14.22

\section{INTRODUCTION}

The pharmacy practice system is in charge of drug therapy to obtain definitive results that improve the quality of life of the patients. Pharmacists play an important role in providing direct patient care by promising the rational use of medicine and promoting cost-effective generic medication use. ${ }^{1}$ Pharmacists also play a role in prescribing and delivering pharmaceutical care services, due to which they are involved in patient care. Since pharmacists are considered well-versed with drugs, they are experts in resolving, recognizing, and preventing drug-related problems. Also, pharmacists can recommend cost-effective medications and provide counselling to patients regarding drug treatment. The rising cost of prescribing medications made pharmacists play a major role in advising both patients and prescribers regarding the use of cost-effective generic medications. ${ }^{2}$

A generic drug is a pharmaceutical product usually interchanged with branded medicine. But it is possible to manufacture after the patent protection of the branded medicine expires. The therapeutic action of generic drugs is identical to their counterpart branded drugs. Hence generic drugs will only be accessible after the expiration of patent protection of the branded medicines. After the patent protection is expired, companies other than the innovator company can manufacture those generic drugs. These generic medicines are equivalent to branded medicines in the matter of their safety, cost-effectiveness, dosage form and strength, route of administration, and indication used. However, they might differ in some conditions like safety and packaging. ${ }^{1}$

Increasing pharmaceutical expenses in health care systems made it necessary to introduce a series of simultaneous policies in which generic pharmaceuticals (generics) instead of expensive branded originators are majorly seen. Generics and branded originators have the same active ingredient but differ in the excipients used. It is necessary to submit bioequivalence studies of the generics to confirm its equivalence to the branded originator regarding its pharmacokinetic properties. Several studies reported that by increasing prescribing of patented versus generic products, it was considered essential at its therapeutic doses, and it is related to significant savings. ${ }^{3}$

A large proportion of the budget related to health, in most developing countries, proceeds to purchase drugs required to treat illness of the public health. Hence, the approach to therapy is questioned based on the availability of inexpensive medications. Affordability is often hindered due to the higher cost of these medications. To improve access, many developing and developed countries have initiated measures to reduce the expenses of drugs. One of the approaches includes encouraging generic medication use among healthcare professionals.

Studies indicated that it is a challenge to alter the perspectives and the pattern of prescribing and dispensing practice of generic medications among healthcare professionals. Hence, it is necessary to educate to

This is an open access article distributed under the terms of the Creative Commons Attribution-NonCommercial-ShareAlike 4.0 License, which allows others to remix, tweak, and build upon the work non-commercially, as long as the author is credited and the new creations are licensed under the identical terms. 
alter, specifically for the upcoming healthcare professionals, since their present perception of prescribing generic medications can affect the further prescribing patterns. These interventions have been suggested in developed and some developing countries to promote generic medication use. ${ }^{4}$

The use of generic medicine is very important to reduce rising health care cost, proper knowledge of pharmacy students towards generic medicines are important. The present study was conducted to assess and compare the awareness of first-year with fourth-year bachelor of pharmacy students about generic medicines.

\section{MATERIALS AND METHODS}

A prospective cross-sectional questionnaire-based study conducted among 200 bachelor of pharmacy undergraduates from September 2019 to November 2019 at a college in coastal region of Karnataka, India after obtaining approval from Institutional Ethics Committee (NGSMIPS/ IEC/27/2019). A questionnaire was used to assess awareness about generic medicine among first year and fourth year bachelor of pharmacy students. Those who were present on the day of data collection and willing to take part were involved in the study. Those who were absent, unwilling to participate, or did not return the questionnaire within the specified time were excluded. An awareness questionnaire containing 10 questions was designed, and pharmacy teachers validated it before starting the study. After updating about the study, the questionnaire was distributed to first- and fourth-year students during one of their classes and asked them to complete the questionnaire anonymously. The participants' awareness was assessed by using "yes" to "no" and "don't know" answers. Simple descriptive statistics were used to generate frequencies, percentages, and proportions. Microsoft Excel was used to analyze the data.

\section{RESULTS}

Out of 200 students, all 200 (100\%) students participated in the study. The analysis was done using "yes", "no", "don't know" type options for assessing knowledge.

\section{Availability of medicines by Jan Aushadi}

Out of 200 students, 199 (99.5\%) students answered that generic drugs are available in Jan Aushadi and $1(0.5 \%)$ student think that branded drugs are available in Jan Aushadi. In contrast, none of the students answered both. Out of the all students, $4^{\text {th }}$-year students have more awareness about the availability of the drug in Jan Aushadi than $1^{\text {st }}$-year students. Results are shown below in the Table 1.

\section{Awareness about price variability}

According to the study conducted, it can be seen that out of 200 student's 197 (98.5\%) students think that there is a price variation between generic drugs and branded drugs, whereas $3(1.5 \%)$ students opted against it among $1^{\text {st }}$ year students. $99(49.5 \%)$ students from $4^{\text {th }}$-year students have

Table 1: Distribution of subjects on the understanding of availability of medicines by Jan Aushadi.

\begin{tabular}{lcc}
\multicolumn{1}{c}{ Awareness statement } & \multicolumn{2}{c}{ Students' response $(n=200)$} \\
\hline & $1^{\text {st }}$ year students & $4^{\text {th }}$ year students \\
\hline $\begin{array}{l}\text { Which among the following is } \\
\text { provided by Jan Aushadi? }\end{array}$ & & \\
a) Generic drugs & 99 & 100 \\
b) Branded drugs & 1 & 0 \\
\hline
\end{tabular}

opted yes as compared to 99 (49\%) $1^{\text {st }}$-year students. The detailed report is shown in Table 2.

\section{Awareness about equivalency between generic and branded drugs}

The result found that 191 (95.5\%) students agreed that generic medicines are equivalent to branded drugs compared to 5 (2.5\%) students who did not agree. Compared of $1^{\text {st }}$-year students, 4 th-year students, have better awareness of equivalent about branded and generic drugs. The detailed report is shown in Table 2.

\section{Awareness about quality}

The study showed that students disagree that generic drugs have a different quality than branded drugs. $1^{\text {st }}$-year students $(38.5 \%)$ have better awareness than $4^{\text {th }}$-year students $(12 \%)$. The detailed report is shown in Table 2.

\section{Awareness about effectiveness}

Out of 200 students, 8 (4\%) students have agreed that there is no difference in the effectiveness of generic drugs and branded drugs compared to 188 (94\%) students who do not agree. Both $1^{\text {st }}$ year and $4^{\text {th }}$-year students have better awareness about the effectiveness of the drugs. The detailed report is shown in Table 2 .

\section{Awareness about drug duration of action}

From the study, it is found that 79 students (39.5\%) did not agree that generic drugs have a long duration of action than branded drugs, which is too high compared to 14 students $(7 \%)$ who think that generic drugs have a longer duration of action than branded drugs, and 107 students (53.5\%) neither agreed nor disagreed. Details of the report are shown in Table 2 .

\section{Awareness about manufacturing facilities}

About the manufacturing facilities, students had mixed opinions, 133 (66.5\%) students believe that both branded and generic drugs are made in same manufacturing facilities in that majority of the students are in $4^{\text {th }}$ year (72) whereas 53 students have a strong opinion that branded drugs are made in modern manufacturing facilities. In contrast, generic drugs are often made in substandard manufacturing facilities in that majority are $1^{\text {st }}$-year students (61). The detailed report is shown in Table 2.

\section{Awareness about side effects}

$96(48 \%)$ of the students do not know about the side effects of drugs, whereas $24(12 \%)$ students think that generic drugs produce more side effects than brand drugs, while the remaining 80 (40\%) students do not agree with it. The detailed report is shown in Table 2.

\section{Awareness about safety standards}

137 (68.5\%) students think that branded medicines must meet higher safety standards than generic medicines compared to 35 (17.5\%) students who disagree with it. Details of this report are shown below in Table 2.

\section{Awareness of availability of drugs}

Out of 200 students, 116 (58\%) students, generic drugs are easily available in the market compared to branded drugs, whereas 41 (20.5\%) are against it followed by $43(21.5 \%)$ students who don't know about it. Detailed results are shown below in Table 2. 
Table 2: Distribution of subjects on the understanding of price variability, equivalency between generic and branded drugs, quality, effectiveness, drug duration of action, manufacturing facilities, side effects, safety standards and availability of drugs.

\begin{tabular}{|c|c|c|c|c|c|c|c|c|c|c|c|c|}
\hline \multirow{4}{*}{ Awareness statement } & \multicolumn{12}{|c|}{ Answer } \\
\hline & \multicolumn{4}{|c|}{ Yes } & \multicolumn{4}{|c|}{ No } & \multicolumn{4}{|c|}{ Don't know } \\
\hline & \multicolumn{2}{|c|}{$\begin{array}{l}1^{\text {st }} \text { year } \\
\text { students }\end{array}$} & \multicolumn{2}{|c|}{$\begin{array}{l}4^{\text {th }} \text { year } \\
\text { students }\end{array}$} & \multicolumn{2}{|c|}{$\begin{array}{l}1^{\text {st }} \text { year } \\
\text { students }\end{array}$} & \multicolumn{2}{|c|}{$\begin{array}{l}4^{\text {th }} \text { year } \\
\text { students }\end{array}$} & \multicolumn{2}{|c|}{$\begin{array}{l}1^{\text {st }} \text { year } \\
\text { students }\end{array}$} & \multicolumn{2}{|c|}{$\begin{array}{l}4^{\text {th }} \text { year } \\
\text { students }\end{array}$} \\
\hline & $\mathbf{n}$ & $\%$ & n & $\%$ & $\mathrm{n}$ & $\%$ & $\mathrm{n}$ & $\%$ & n & $\%$ & $\mathrm{n}$ & $\%$ \\
\hline Do you think there is price difference between branded and generic drugs? & 98 & 49 & 99 & 49.5 & 2 & 1 & 1 & 0.5 & 0 & 0 & 0 & 0 \\
\hline Do you think that generic drugs are equivalent to branded medicines? & 95 & 47.5 & 96 & 48 & 2 & 1 & 3 & 1.5 & 3 & 1.5 & 1 & 0.5 \\
\hline Do you think that generic drugs have different quality than branded medicines & 4 & 2 & 18 & 9 & 77 & 38.5 & 80 & 40 & 19 & 9.5 & 2 & 1 \\
\hline Do you think generic drugs are less effective than branded drugs? & 5 & 2.5 & 3 & 1.5 & 92 & 46 & 96 & 48 & 3 & 1.5 & 1 & 0.5 \\
\hline Do you think that generic drugs have long duration of action than branded drugs? & 8 & 4 & 6 & 3 & 66 & 33 & 13 & 6.5 & 26 & 13 & 81 & 40.5 \\
\hline $\begin{array}{l}\text { Do you think that branded drugs are made in modern manufacturing facilities } \\
\text { whereas generic drugs are often made in substandard manufacturing facilities? }\end{array}$ & 28 & 14 & 25 & 12.5 & 61 & 30.5 & 72 & 36 & 11 & 5.5 & 3 & 1.5 \\
\hline Do you think that generic drugs produce more side effects than brand drugs? & 11 & 5.5 & 13 & 6.5 & 22 & 11 & 58 & 29 & 67 & 33.5 & 29 & 14.5 \\
\hline $\begin{array}{l}\text { Do you think that branded medicines are required to meet higher safety standards } \\
\text { than generic medicines? }\end{array}$ & 64 & 32 & 73 & 36.5 & 22 & 11 & 13 & 6.5 & 14 & 7 & 14 & 7 \\
\hline $\begin{array}{c}\text { Do you think that generic drugs are easily available in market compare to branded } \\
\text { drugs? }\end{array}$ & 55 & 27.5 & 61 & 30.5 & 22 & 11 & 19 & 9.5 & 23 & 11.5 & 20 & 10 \\
\hline
\end{tabular}

\section{DISCUSSION}

This study shows that a good percentage of students had awareness about generic medicines and had a good attitude about the efficacy, safety, and quality of generic medicines. These findings are similar to the study regulated by Bhattacharjee $\mathrm{P}$ et al. ${ }^{5}$

The majority of students think that generic drugs are important in minimizing health care expenditure. The price of generic drugs is a key matter in reducing health costs. Indian health care system the price of generic drugs has much lower price than the branded drugs, so proper use of generic drugs in health care will affect the branded drugs. As a result, there may be changes in the prices of branded drugs. Generic medicines need not have to go through the costliest clinical trials it undergoes reasonable clinical trials that are required for approval from the regulatory authorities, which ultimately helps in reducing the price of generic drugs but also will not raise doubt about the efficacy, quality, and safety of drugs. ${ }^{5}$

From this study, most students agreed with the safety and efficacy of generic drugs. However, they know about the preclinical and clinical studies regulations required to initiate generic medicines. Generic drugs are as safe and effective as branded drugs because regulatory authorities will approve after fulfilling the requirements before marketing the products. Generic drugs are manufactured according to the Good Manufacturing Practice guidelines before drugs are out on the market. The manufacturer should give information about the facilities used for the production process and finish generic manufacturing drugs. ${ }^{6}$

More students did not approve that generic drugs are made in substandard manufacturing facilities in this study. In the present study, about $92.1 \%$ of the participants believe that every hospital should have a generic medicine store. The patient should have the freedom to choose generic medicines over branded drugs. Interestingly, there should be a training program among doctors and patients to raise awareness regarding generic medicines. Also, most of the participants believe that generic medicines should be trained in the early part of the internship. In this study, the majority believe that quality testing of generic drugs should be made more vigorous, similar to the result of another study conducted by Shrank WH et al.?
According to our study, about $92 \%$ of participants were aware of the Jan Aushadhi scheme of Government. of India, whose purpose is to set up generic medicine stores around the country and minimize the cost of health care, which supports the findings of Bhattacharjee $\mathrm{P}$ et al. ${ }^{5}$

\section{CONCLUSION}

The use of generic medicines decreases the cost of treatment and encourages the rational use of medicines. Pharmacy students have good knowledge about generic medicines, but some still lack awareness about generic medicines. It can be clearly seen that fourth-year students have slightly better awareness than first-year students. There was a significant gap concerning the awareness about generic medicines. Studies among pharmacy students in the institution are required. More scientific work should be conducted about how the interventions for students and the community can improve generic medicines' knowledge, awareness, and acceptability. Awareness gaps about the use of generic medicines exist, and they must be modified through appropriate education. Deficiencies were noted, and we have to strengthen learning about generic drugs during the coming years.

\section{ACKNOWLEDGEMENT}

We authors would like to thank NITTE (Deemed to be University), Justice K. S. Hegde Charitable Hospital and N.G.S.M Institute of Pharmaceutical Sciences, Mangaluru, Karnataka for providing us with all the necessary facilities for carrying out this work.

\section{REFERENCES}

1. Mohammed AS, Woldekidan NA, Mohammed FA. Knowledge, attitude, and practice of pharmacy professionals on generic medicines in Eastern Ethiopia: A cross-sectional study. PLOS ONE. 2020;15(7):e0235205. doi: 10.1371/journal. pone.0235205, PMID 32658918.

2. Othman GQ, Abdulghani MA. Assessment of knowledge and perceptions of generic medicines among pharmacy students in Yemeni universities. Pharm Educ. 2015;22:15.

3. Souliotis K, Golna C, Kani C, Markantonis S. Exploring knowledge and perceptions on generic drugs of final year pharmacy school students in Greece. Expert Rev Pharmacoecon Outcomes Res. 2019;19(5):569-74. doi: 10.1080/14737167.2019.1571412, PMID 30658041. 
4. James PB, Bah AJ, Margao EK, Hanson C, Kabba JA, Jamshed SQ. Exploring the knowledge and perception of generic medicines among final year undergraduate medical, pharmacy, and nursing students in Sierra Leone: A comparative cross-sectional approach. Pharmacy (Basel). 2018;6(1):3. doi: 10.3390/pharmacy6010003, PMID 29300350.

5. Bhattacharjee P, Das L, Ghosh R, Das UK, Chakraborty M. Knowledge, attitude and practice of generic medicines among doctors in a tertiary care teaching hospital of Tripura, India. Int J Basic Clin Pharmacol. 2017:6(6):1287. doi: 10.18203/2319-2003.ijbcp20172040.
6. Wong ZY, Hassali MA, Alrasheedy AA, Saleem F, Yahaya AH, Aljadhey H. Patients' beliefs about generic medicines in Malaysia. Pharm Pract. 2014;12(4):474. doi: 10.4321/s1886-36552014000400006, PMID 25580171.

7. Shrank WH, Hoang T, Ettner SL, Glassman PA, Nair K, DeLapp D, Dirstine J, Avorn J, Asch SM. The implications of choice: prescribing generic or preferred pharmaceuticals improves medication adherence for chronic conditions. Arch Intern Med. 2006;166(3):332-7. doi: 10.1001/archinte.166.3.332, PMID 16476874.

Article History: Received: 15-12-2021; Revised: 02-01-2022; Accepted: 17-01-2022

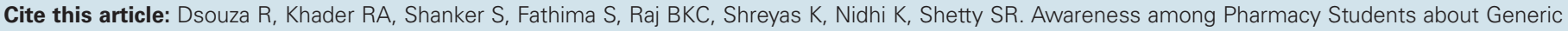
Medicines: A Cross-sectional Study. J Young Pharm. 2022;14(1):118-21. 